\title{
Dental concerns of children with intellectual disability - A narrative review
}

\author{
SVSG Nirmala ${ }^{1 *}$, Degala Saikrishna ${ }^{2}$ and Sivakunar Nuvvula ${ }^{1}$ \\ ${ }^{1}$ Department of Paedodontics \& Preventive Dentistry, Narayana Dental College \& Hospital, Nellore, Andhra Pradesh, India \\ ${ }^{2}$ Department of Oral and Maxillofacial Surgery, JSS Dental College and Hospital, Mysore, India
}

\begin{abstract}
Intellectual Disability is a general term is applied to person whose intellectual development is significantly lower than that of normal people and whose ability to adapt to their environment is consequently limited, $1.3 \%$ of the population is affected and factors which play an important role are environmental, chromosomal and monogenic. It may be associated with syndromes like Down syndrome. Clinical manifestations are tensely reclined head, poor mobility, increased tone in limbs, persisting fisting and abnormal behaviour. Self-mutilation (biting, head banging and scratching), hunger for non-food items such as dirt, hair etc. Salivary flow is altered due to the multiple medications leads to Early Childhood caries. Increased plaque and calculus formation which give rise to poor oral hygiene further leads to halitosis. Early loss of anterior teeth leads to speech impairment. Congenitally missing permanent teeth and enamel hypoplasia fractured anterior teeth. More prone for self injurious habits like Lip biting and they tend to yearn for non-food items such as dirt and hair etc. Material for the carious teeth is glass ionomer cement due to the fluoride release; stainless steel crowns are beneficial for multi surface carious teeth. Single visit endodontic treatment is considered, an apex locator would be helpful rather radiographs for working length. Fixed prosthodontics is more appropriate than removable partial dentures. Powered tooth brushes are relatively preferable than conventional tooth brushes. If the child is having drug induced gingival over growth and interferes the occlusion gingivectomy is the treatment of choice. Some anxious children Desensitization is effective in the first line of treatment and restraints can be used when other types of techniques failed. Mouth props can be used during the treatment. A child who cannot be managed with physical restraints oral sedation with vallium, chloralhydrate, and hydrazine is useful to reduce the anxiety during treatment. General anesthesia is the last resort in behavior management in these children. This article discusses about etiology, clinical features along with dental management.
\end{abstract}

\section{Introduction}

Intellectual Disability. (ID) also called as intellectual development disorder (IDD) or general learning disability and in earlier times known as mental retardation (MR) [1].

Intellectual Disability is a disability characterized by significant limitations both in intellectual functioning and in adaptive behavior, which covers many everyday social and practical skills. This disability originates before the age of 18 , intellectual functioning also called intelligence- refers to general mental capacity, such as learning, reasoning and problem solving and so on $[2,3]$.

According to American Academy of Pediatric Dentistry Intellectual disability (ID) or is defined as "a condition of arrested or incomplete development of the mind, which is specially characterized by impairment of skills manifested during the developmental period, which contribute to the overall level of intelligence, i.e. Cognitive, language, motor, and social abilities" [3,4].

Nearly $3 \%$ of the world's population has some form of ID. Among those with ID mild (85\%), moderate (10\%), severe (4\%) and profound (2\%) respectively [5,6]. Reported incidence in U.S and Finland as $9.1 \%$ and $12.6 \%$ per 1000 population however, the mortality rate is higher with severe form rather than other forms of Intellectual Disability $[7,8]$.

In Britain, the mental health act of 1960 abolished this classification and substituted the terms of subnormality and severe subnormality. In the latter group are those persons who are incapable of leading an independent life while the former requires special care but not dependent to the extent of the severely afflicted. There is great confusion in the terminology and WHO recommends general term 'mental subnormality' with the addition of 'mild', 'moderate', or 'severe'. For general usage but without displacing any clinical nomenclature. the term recommended are, therefore: [9-13]

1. Mild subnormality with IQ of 50-69, and mental age of 8-12

2. Moderate subnormality with IQ of 20-49, and mental age of 3-7 years

3. Severe subnormality with IQ of -19 , and mental age of -2 years

4. Profoundly Retarded - Those children have IQ scored below 20 and totally [0] reliant on others for their personal needs [9-13]

The etiology of Intellectual disability covers the large number of factors which maybe divided broadly into hereditary and environmental. the hereditary aspect of causation is an important and there is a high incidence of defective parents who produce defective children this group also includes recognized conditions in which mental deficiency occurs, such as phenol ketonuria, cretinism, defmutism, microcephaly, neurofibromatosis, and huntington's chorea. Mongolism may be due in a few cases to an inherited defect but in majority in a chromosomal error. environmental factors affecting mental development include

${ }^{\star}$ Correspondence to: SVSG Nirmala, Professor, Department of Paedodontics \& Preventive Dentistry, Narayana Dental College \& Hospital, Nellore, Andhra Pradesh 524003, India, E-mail: nimskrishna2007@gmail.com

Key words: children, dental management, intellectual disability, oral health

Received: July 23, 2018; Accepted: August 10, 2018; Published: August 13, 2018 
infections in the prenatal, perinatal and post-natal periods: maternal rubella in third $\mathrm{m}$ month and other viral infections; fetal irradiation rhesus incompatibility, bacterial meningitis and viral encephalitis in the perinatal period and childhood; anoxia at the time of delivery and traumatic injury to the brain the delivery or subsequently. In many cases investigation may disclose a number of possible etiological factors [14-16].

Intellectual disability may not be recognized at birth, but attention is later attracted to the slowness of development and except in severe case a reasonably accurate assessment of the mental level is not possible for some years. it is recognized that it is better for mentally subnormal child to remain within the family even in severe cases if it is at all possible and $\mathrm{f}$ or as long as possible, having fully assessed the parent's competence and the family implications. Such patients domiciled at home are supervised by a public nurse and they may attend a training or occupational centre daily [17-19].

\section{Clinical features}

- Hyper activity

- Impulsiveness

- Distractibility

- Fearful behavior

- Self mutilation and Craving for non-food items

\section{Oral condition}

Because of poor oral hygiene and soft diet which occurs in this type of patient, the caries rate tends to be a little higher than average and the periodontal condition poor. Apart from this only the mongoloid child shows any special features.

\section{Dental caries}

Depending on the local oral environment, diet, home care, and other factors children with ID development caries rate is same as the normal children but the prevalence rate of untreated caries are higher than normal children. Due to the frequent medications in the form of syrups, these children have early childhood caries.

- Salivary flow is altered due to the multiple medications, increased plaque and calculus formation which give rise to poor oral hygiene further leads to halitosis.

- Congenitally missing permanent teeth and enamel hypoplasia fractured anterior teeth and soft tissue complications are more commonly seen.

- Lip biting is most commonly seen. Abnormal jaw growth, Loss of space in the permanent dentition leads to malocclusion.

- Speech impairment due to the early loss of teeth.

Maintenance of oral hygiene is often a task for these children leads to higher rate of gingivitis and periodontal ID diseases.

\section{Dental management}

Medical History is very essential with these children to know which type of ID and associated medical problems. Information should be gathereded from the parents/ care givers about the usage of drugs.

\section{Behavioral history}

Complete information should be obtained from the parents/ caregivers regarding the level of communication of the child, what are the functions he can perform individually and also whenever there are behavior problems at home/institution [20-22].

\section{Restorations}

Children with Intellectual disability, emphasis should be made on decreasing the incidence of new caries lesion in addition to restore the carious teeth.

The preferred material for the carious teeth is glass ionomer cement due to the fluoride release; multi surface carious teeth stainless steel crowns are beneficial.

Single visit endodontic treatment is considered, as working length radiographs would be difficult to obtain, an apex locator would be helpful.

\section{Prosthetic considerations}

Fixed prosthodontics is more appropriate than removable partial dentures. Less time is required for tooth preparation in resin bonded bridges which are more useful.

Removable partial dentures and complete dentures are contraindicated for children whose seizures are poorly controlled.

\section{Periodontal considerations}

Powered tooth brushes are preferable rather than conventional tooth brushes. reinforce the method of tooth brushing to the parents as well as caregivers.

Mouth wash or rinse should be used in an appropriate method as gargle might not work with all the patients especially with impaired swallowing reflex.

If patient is on medication like sodium valporate or phenytoin regular professional prophylaxis is needed. If the child is having drug induced gingival over growth and interferes the occlusion gingivectomy is the treatment of choice but periodontal packs may not be well tolerated and to overcome this electro surgery or laser surgery is preferred.

\section{Behavior management}

Some anxious children Desensitization is effective in the first line of treatment and restraints can be used when other types of techniques failed. Physical restraints to control the movements of extremities, mechanical restraints like papoose board, Pedi- wraps, tape straps, mouth props can be used during the treatment.

A child who cannot be managed with physical restraints oral sedation with valium, chloral hydrate, and hydrazine is useful to reduce the anxiety during treatment.

General anesthesia should be the last resort in behavior management in this children [23]

The child with mild degree of mental subnormality can be treated in the dental surgery as part of his own family without great difficulty, his mental level should be known so that the dentists approach can be adjusted accordingly and the treatment plan should be modified to his degree of tolerance. Patience is the main asset in the treatment of these children, but where cooperation is poor, oral rehabilitation under general anesthesia should be considered. Children with brain damage due to anoxia or those who are prone to convulsions may not be considered as suitable subjects by the anesthetists. Current drug therapy such as anti-consultants or tranqillizers taken into consideration and if there is any doubt, the physician should be consulted [24-26]. 
Need for Prevention of dental disease is one of the few problems encountered by special individuals that can be controlled. Good dental health is important for mastication, digestion, appearance, speech and general health.

\section{Preventive strategies}

Children with ID oral health play an important role for appearance, speech, mastication and digestion etc. and the preventive measures like brushing method, dietary counselling and fluoride supplementation is very essential. These children have involuntary hand and arm movements hence they are not able to brush their teeth. Thus, it is necessary to take the responsibility of parents/caregivers about this.

Following measure are recommended for prevention of dental caries and periodontal disease in these individuals [27-29].

\section{Tooth brushing}

Based on the degree of ID and physical handicap the tooth brush and brushing technique should be selected and modifications of tooth brushes which require minimal manual dexterity are available in the market.

Mouth props are used for gaining access to teeth for these children. Floss can be used to remove inter proximal plaque and floss holder can be used in children with minimal manual dexterity. Although these children reside in fluoridated water they don't drink more water to get complete benefits of fluoride and hence they require fluoride supplementation [30-32]. To get a maximum protection against dental caries professional topical fluoride applications can be combined with home-use fluoride. Depending upon the need and ability of these children home use fluoride can be given in the form of chewable tablets, gels and rinses etc. [31].

Chlorehexidine which is a chemical plaque control can be used as a mouth wash for these children with care, studies have proved that it is very affective to maintain oral hygiene of these children $[11,12]$.

\section{Dietary counseling}

Most of the children ingest soft diet which contains refined carbohydrates and to control the behavior sweetened foods are used as a reward. Hence, parents/caregivers should be counselled regarding the effects this type of food.

The periodontal condition of these children requires special attention while tooth brushing is difficult but extremely important. The use of battery operated brush is of great help to the patient or the parent is she is the operator.

The use of restraints is acceptable while treating these children, should not be used as a punishment, no physical injury to the patient. Restraint can be classified as physical restraint refers to the one person taking a physical control over another person's arms legs or head to minimize movements during treatment and prevents self-injury [32].

The more handicapped child is unlikely ever to be able to tolerate dentures to replace lost teeth and more teeth he loses the greater the difficulty of eating proper foods. He will therefore towards poorer type of diet. The possibility of rehabilitate under general anasesthesia must be seriously considered in these cases [33].

Kind approach of the dentist through communication can change the maladaptive behavior of these children and positive reinforcement as praise the child, pat on the back or smile etc. aids to shape the behavior of these children [10].

\section{Behavioral guide lines}

Children with ID can be effectively treated in the dental office as followed [34,35]:

- Pre-appointment should be planned either in person/phone.

- Early in the morning appointments are preferred rather than in the afternoon or evening.

- Regarding the level of Intellectual Disability and functional abilities of the child should be discussed with parents / caregivers. Children with ID associated with Down syndrome understand more than they can verbalize.

- Instructions should be short, clear and repeat when it is needed. Give same terms to compensate short term memory difficulties.

- Minimize sounds and light music will calm the child.

- Oral examination should be started gently with one finger in the beginning followed by using dental instruments.

- Whenever new instruments and products are using for children with ID, use TSD technique.

- Children who are unable to understand verbal instructions demonstration may be mandatory.

- For cooperative children reward them with new tooth brush, sticky notes, balloons, toys etc. at the end of the treatment.

- Maintain the primary teeth as long as possible.

- Whoever [either parent/caregiver] given the informed consent make sure they should be present during the treatment.

- Use chlorhexidine mouth wash to reduce the microbial load, if the child is able to rinse with antimicrobial agent or spray application would be more suitable.

- Whenever there is history of self-injurious habits, use mouth guards.

- Staff should be trained to manage children with ID. Use same staff in the dental operator in each visit.

Dental treatment and prevention [36]:

- Determine who give informed consent. Sure, they are present the can Be at appointment.

- Monitor periodontal disease and caries activity closely.

- Consider prescribing Chlorhexidine or other antimicrobial agents for daily use. Determine patient able to rinse with the agent a spray if is or if application would be more appropriate.

- Evaluate malocclusions. Some patients are good candidates for full orthodontic treatment. Maintain primary teeth (if present) as long as possible and consider space maintenance and orthodontic consultation for missing teeth.

- A power toothbrush, if tolerated, can be an effective oral hygiene tool.

- A mouth guard (if tolerated) may be useful for cases involving it can be bruxism, self-injurious behaviors, or mouth trauma.

\section{Conclusion}

Making difference in the oral health of a child with ID may go slowly at first, but determination can bring positive results and invaluable 
rewards. Pediatric dentist can create significant impact not only the oral health of these children but also their quality of life.

\section{References}

1. Pinkham, Cassamassimo, Fields, McTigue, Nowak - Pediatric Dentistry Infancy through Adolescence. 4th edition, W.B. Saunders Publications.

2. Jeffery A. Dean, Ralph E McDonald, David R. A very - Dentistry for child and adolescent 9th Edition, Elsevier Publications.

3. World Health Organization (2001) The International classification of functioning, disability and health (ICF). Geneva: World Health Organization.

4. American Association on Intellectual and Developmental Disabilities (2010). http:// www.aamr.org/content_100.cfm?navID=21. Accessed June 28, 2018.

5. DeBiase CB. (1991) The disabled. In: Dental health education: theory and practice. Philadelphia: Lea \& Febiger.

6. Harris JC (2006) Intellectual disability: Understanding its development, causes, classification, evaluation, and treatment. New York: Oxford University Press. pp 42-98.

7. King BH, Toth KE, Hodapp RM, Dykens EM (2009) Intellectual disability. In B. J. Sadock, V. A. Sadock, \& P. Ruiz (Eds.), Comprehensive textbook of psychiatry (9th ed., pp. 3444-3474). Philadelphia: Lippincott Williams \& Wilkins.

8. Katusic SK, Colligan RC, Beard CM, O'Fallon WM, Bergstralh EJ, et al. (1996) Mental retardation in a birth cohort, 1976-1980, Rochester, Minnesota. American Journal of Mental Retardation 100: 335-344.

9. Nowak AJ, Casamassimo PS, Slayton RL (2010) Facilitating the transition of patients with special health care needs from pediatric to adult oral health care. J Am Dent Assoc 141: 1351-1356. [Crossref]

10. Glassman P, Subar P (2009) Planning dental treatment for people with special needs. Dent Clin North Am 53: 195-205, vii-viii. [Crossref]

11. Steinberg BJ (2005) Issues and challenges in special care dentistry. J Dent Educ 69: 323-324. [Crossref]

12. Weddell JA, McKown CG, Sandres BJ, Jones JE (1994) Dental problems of the disabled child. In: McDonald RE and Avery DR (Eds.) Dentistry for the Child and Adolescent (6th Ed). Mosby. St. Louis. p 592-594.

13. World Health Organization (2001) The International classification of functioning, disability and health (ICF). Geneva: World Health Organization.

14. Anders PL, Davis EL (2010) Oral health of patients with intellectual disabilities: a systematic review. Spec Care Dentist 30: 110-117. [Crossref]

15. Gizani S, Kandilorou H, Kavvadia K, Tzoutzas J (2012) Oral health care provided by Greek dentists to persons with physical and/or intellectual impairment. Spec Care Dentist 32: 83-89.

16. Desai M, Messer LB, Calache H (2001) A study of the dental treatment needs of children with disabilities in Melbourne, Australia. Aust Dent J 46: 41-50. [Crossref]

17. Koneru A, Sigal MJ (2009) Access to dental care for persons with developmental disabilities in Ontario. J Can Dent Assoc 75: 121. [Crossref]

18. Gordon SM, Dionne RA, Snyder J (1998) Dental fear and anxiety as a barrier to accessing oral health care among patients with special health care needs. Spec Care Dentist 18: 88-92. [Crossref]
19. Ferreira MC, Guare RO, Prokopowitsch I, Santos MT (2011) Prevalence of dental trauma in individuals with special needs. Dent Traumatol 27: 113-116. [Crossref]

20. American Academy of Pediatric Dentistry (2012) Guideline on caries-risk assessment and management for infants, children and adolescents. Pediatr Dent 34: 118-125.

21. American Academy of Pediatric Dentistry (2012) Policy on interim therapeutic restorations (ITR). Pediatr Dent 34: 48-49.

22. American Academy of Pediatric Dentistry (2012) Guideline on fluoride therapy Pediatr Dent 34: 162-165.

23. American Academy of Pediatric Dentistry (2012) Guideline on pediatric restorative dentistry. Pediatr Dent 34: 214-221.

24. American Academy of Pediatric Dentistry (2012) Policy on dietary recommendations for infants, children, and adolescents. Pediatr Dent 34: 56-58.

25. Yilmaz S, Ozlü Y, Ekuklu G (1999) The effect of dental training on the reactions of mentally handicapped children's behavior in the dental office. ASDC J Dent Child 66 : 188-191, 154-5. [Crossref]

26. Stiefel DJ, Stull DE (1982) Consideration in care of the patient with a disability. In Ingersoll BD, ed. Behavioral aspects in dentistry. Norwalk, CT: Appleton-CenturyCrofts.

27. Raposa KA (2009) Behavioral management for patients with intellectual and developmental disorders. Dent Clin North Am 53: 359-373. [Crossref]

28. Purohit BM, Acharya S, Bhat M (2010) Oral health status and treatment needs of children attending special schools in South India: a comparative study. Spec Care Dentist 30: 235-241.

29. Kleinert HL, Sanders C, Mink J, Nash D, Johnson J, et al. (2007) Improving student dentist competencies and perception of difficulty in delivering care to children with developmental disabilities using a virtual patient module. J Dent Educ 71: 279-286.

30. Anders PL, Davis EL (2010) Oral health of patients with intellectual disabilities: a systematic review. Spec Care Dentist 30: 110-117. [Crossref]

31. Weddell JA, McKown CG, Sandres BJ, Jones JE (1994) Dental problems of the disabled child. In: McDonald RE and Avery DR (Eds.) Dentistry for the Child and Adolescent (6th Ed). Mosby. St. Louis. p 592-594.

32. Waldman HB, Swerdloff M, Perlman SP (1999) Children with mental retardation: stigma and stereotype images are hard to change. ASDC J Dent Child 66: 343-347, 294. [Crossref]

33. Wasserman BS (2009) The special care patient. Preface. Dent Clin North Am 53: xvxvi. [Crossref]

34. Salles PS, Tannure PN, Oliveira CA, Souza IP, Portela MB, et al. (2012) Dental needs and management of children with special health care needs according to type of disability. J Dent Child (Chic) 79: 165-169. [Crossref]

35. Ferguson FS, Cinotti D (2009) Home oral health practice: the foundation for desensitization and dental care for special needs. Dent Clin North Am 53: 375-387, xi. [Crossref]

36. Whyman RA, Treasure ET, Brown RH, MacFadyen EE (1995) The oral health of longterm residents of a hospital for the intellectually handicapped and psychiatrically ill. $N$ Z Dent J 91: 49-56. [Crossref]

Copyright: $@ 2018$ Nirmala SVSG. This is an open-access article distributed under the terms of the Creative Commons Attribution License, which permits unrestricted use, distribution, and reproduction in any medium, provided the original author and source are credited. 